Article

\title{
Coseismic Deformation Mechanisms of the 2021 Ms 6.4 Yangbi Earthquake, Yunnan Province, Using InSAR Observations
}

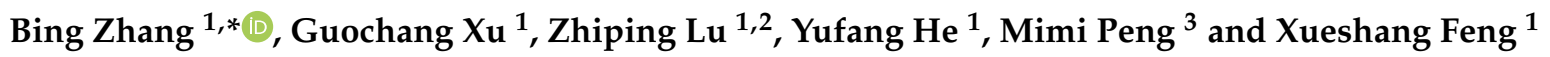 \\ 1 Institute of Space Science and Applied Technology, Harbin Institute of Technology, Shenzhen 518055, China; \\ xuguochang@hit.edu.cn (G.X.); lvzhiping@hit.edu.cn (Z.L.); 19b958025@stu.hit.edu.cn (Y.H.); \\ fengx@spaceweather.ac.cn (X.F.) \\ 2 Institute of Geospatial Information, Information Engineering University, Zhengzhou 450052, China \\ 3 College of Geology Engineering and Geomatics, Chang' an University, Xi'an 710054, China; \\ mmpeng@chd.edu.cn \\ * Correspondence: zhangbing@stu.hit.edu.cn
}

Citation: Zhang, B.; Xu, G.; Lu, Z.; He, Y.; Peng, M.; Feng, X. Coseismic Deformation Mechanisms of the 2021 Ms 6.4 Yangbi Earthquake, Yunnan Province, Using InSAR Observations. Remote Sens. 2021, 13, 3961. https:// doi.org/10.3390/rs13193961

Academic Editor: Franz Livio

Received: 31 July 2021

Accepted: 27 September 2021

Published: 2 October 2021

Publisher's Note: MDPI stays neutral with regard to jurisdictional claims in published maps and institutional affiliations.

Copyright: (c) 2021 by the authors. Licensee MDPI, Basel, Switzerland. This article is an open access article distributed under the terms and conditions of the Creative Commons Attribution (CC BY) license (https:// creativecommons.org/licenses/by/ $4.0 /)$.
Abstract: At 21:48 on 21 May 2021, an Ms 6.4 earthquake occurred in Yangbi County, Dali Prefecture, Yunnan Province. At present, uncertainty remains regarding the source parameters and deformation mechanism of the Yangbi earthquake. In this study, we determine fault geometry and slip distribution of the earthquake by InSAR analysis. Then, the Coulomb stress loading caused by the Yangbi earthquake is further analyzed. The results show that the moment magnitude of the Yangbi earthquake was Mw 6.14. The slip mainly occurred at depths of 3-13 km, with a maximum slip of approximately $61 \mathrm{~cm}$ at a depth of $6.98 \mathrm{~km}$. The Yangbi earthquake was triggered by a blind fault in the NW-SE in the west parallel to the Weixi-Weishan Fault and its seismogenic fault exhibits strike-slip displacement. A large number of aftershocks were distributed along the fault rupture surface where the Coulomb stress increases. As the depth of the crust increases, the area where the Coulomb stress increases in the Yangbi earthquake, decreases. The occurrence of this earthquake also caused a significant increase in the Coulomb stress in the southeastern section of the Weixi-Weishan Faul. We should pay more attention to its seismic hazards.

Keywords: Yangbi earthquake; InSAR; slip distribution; Coulomb stress; Weixi-Weishan fault

\section{Introduction}

At 21:48 on 21 May 2021, an Ms 6.4 earthquake occurred in Yangbi County, Dali Prefecture, Yunnan Province $\left(25.67^{\circ} \mathrm{N}\right.$ and $\left.99.87^{\circ} \mathrm{E}\right)$, with a focal depth of $8 \mathrm{~km}$. As of 22:00 on 22 May 2021, the earthquake caused 35 casualties throughout the state. This was the strongest earthquake in the area after the Ms 5.1 earthquake in 2017.

The network of seismic stations in the area where the earthquake occurred are relatively dense, and there are at least eight broadband fixed seismic stations within a radius of $100 \mathrm{~km}$ from the epicenter [1]. For the two earthquakes of Ms 5.1 and Ms 4.8 in Yangbi, Yunnan Province in 2017, the focal mechanisms were obtained by the cut-and-paste (CAP) method and three different velocity models [2]. The location of the seismogenic fault is further determined by the aftershock sequence relocated by the double-difference positioning method [1]. Therefore, we can obtain the seismic sequence, seismic surface wave velocity and deep structure of the Yangbi earthquake. However, uncertainty remains regarding the source parameters and deformation mechanism of the Yangbi earthquake. So, it is necessary to further study the co-seismic deformation field, the cause of the Yangbi earthquake, the change of Coulomb stress around the earthquake, and the influence on the surrounding faults.

Since the Landers earthquake in 1992, geodetic techniques such as the interferometric synthetic aperture radar (InSAR) and the global navigation satellite system (GNSS) have been widely used in earthquakes and have become more mature. Based on differential 
interferometric synthetic aperture radar (D-InSAR) technology, scholars studied the strong earthquakes of Wenchuan, China, La Quetta, Haiti, New Zealand, Chile, Turkey, Sendai, Nepal, and other countries [3-10]. In the meantime, because the Yangbi earthquake area lacks enough GNSS points, we used the InSAR interferometric technique and Sentinel1A images of ascending and descending tracks to obtain the deformation field of the earthquake region. Then, we calculated rupture parameters and coseismic dislocation distributions and discussed these in combination with geology and geophysics. Then, the influence of the Yangbi earthquake in 2021 on the surrounding area and active faults is discussed by calculating the Coulomb failure stress (CFS) changes.

\section{Tectonic Setting}

The 2021 Ms 6.4 Yangbi earthquake occurred in western Yunnan, China (Figure 1). Since the Cenozoic, the Indian and Eurasian plates have collided, and the Tibetan Plateau has rapidly uplifted [11]. This area lies between the Indochina block and the Yangzi block [12]. It is a vital area for the eastward movement of the Tibetan Plateau material [13]. It has a significant effect on absorption and adjustment to the lithospheric deformation caused by the collision of the Indian plate and the eastward extrusion deformation of the Tibetan Plateau block [12]. At the same time, it also caused extremely active tectonic and seismic activity in the entire Sichuan-Yunnan area [14]. On the other hand, the Sichuan-Yunnan area, as the subduction front of the Indian plate to the Burmese block, has developed large-scale faults that are approximately parallel to the direction of the Burmese arc, such as the Red River fault [15].

Among these, the Red River fault developed in the southeast of Tibetan Plateau [16]. The Sichuan-Yunnan rhombic block takes it as the southwest boundary. The Red River fault also separates the Indo-China block and the Yangtzi block [17]. As of 2 July 2021, according to the records of the International Seismological Center (ISC) (http:/ / www.isc.ac. uk/iscbulletin/, accessed on 2 July 2021) Earthquake Catalogue since 1900, 35 earthquakes of magnitude 5 or more occurred within 100 kilometers of the Yangbi epicenter, of which 33 were of magnitude 5.0 to 5.9 , and 2 were of magnitude 6.0 to 7.9. In the middle section of the fault zone, from Xiaguan to Yangbi, an Ms 7.0 earthquake occurred in 1925 (http:/ / data.earthquake.cn/, accessed on 2 July 2021). Fault structure in the main earthquake area is complex.

To the east of the Yangbi earthquake is the Weixi-Weishan fault, which is parallel to the northern section of the Red River fault. The Red River fault has many lateral ruptures that form a connecting structure complex with the Weixi-Weishan fault. In addition, the Weixi-Weishan fault and the Longpan-Qiaohou fault converge in the Qiaohou area. There are many fault lines and complex structures in the region. At the same time, the Tengchong volcanic area lies to the south. These two reasons are also important for the many aftershocks of the earthquake. 


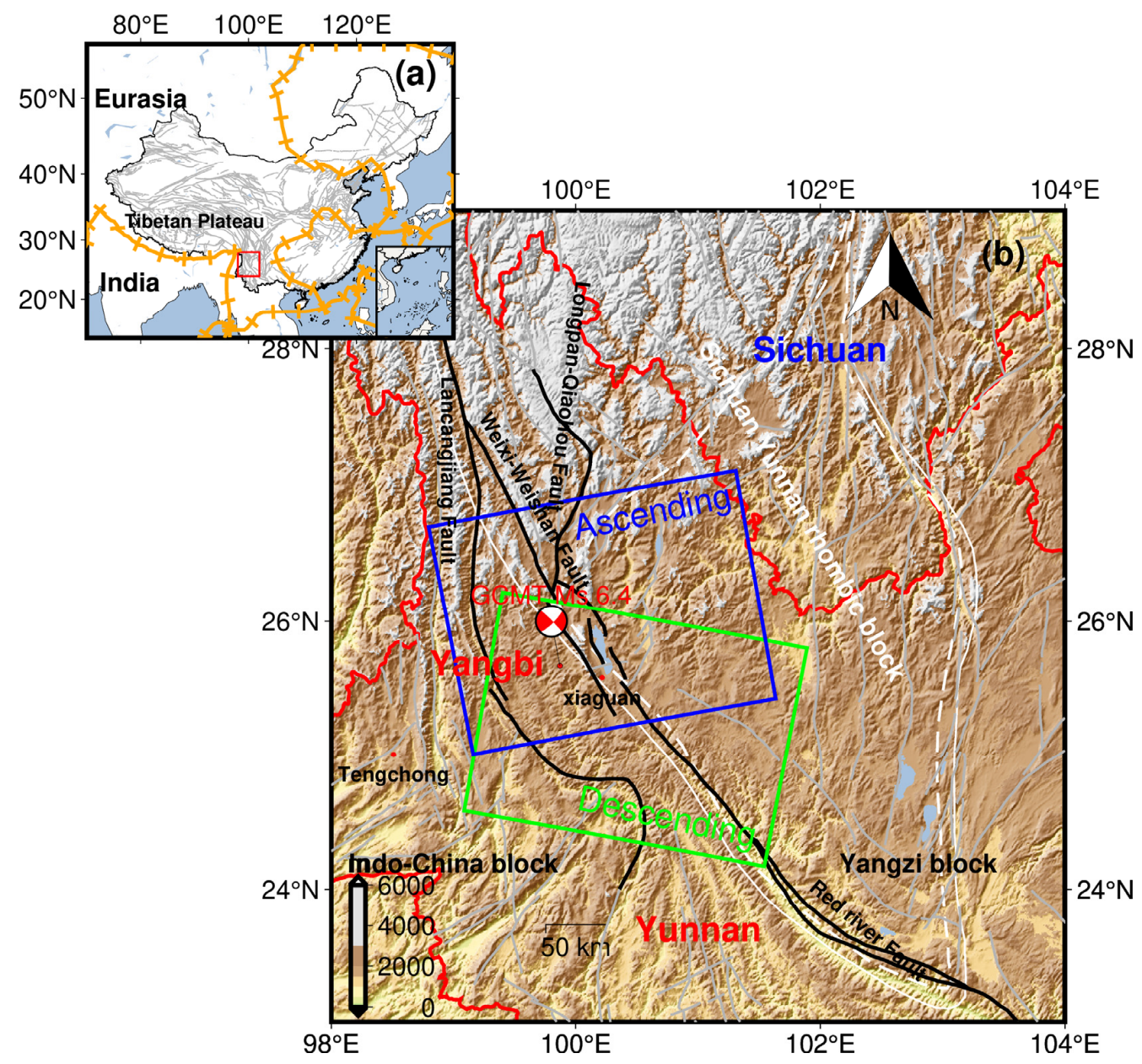

Figure 1. (a) Location of Yangbi and the surrounding region (red box) in China. The orange line represents the plate boundary. (b) Indicates the specific study area. The red beach ball diagram represents the focal mechanism of the Ms 6.4 (GCMT) Yangbi earthquake in 2021. Black lines and grey lines indicate active faults [18]. The blue and green boxes are the coverages of the Sentinel$1 \mathrm{~A}$ ascending and descending images, respectively. The red line indicates the Yunnan provincial boundary. The rhombic block enclosed by the white dotted line is the Sichuan-Yunnan rhombic block.

\section{Methods}

\subsection{InSAR Data and Analysis}

In this study, the two-track radar images of Sentinel-1A in the ESA's Global Monitoring for Environment and Security (GMES) were selected. Sentinel-1 frame coverage is about $250 \times 250 \mathrm{~km}$, completely covering the main deformation area of the Yangbi earthquake (Figure 2). The Sentinel-1A satellite data parameters used in this paper are shown in Table 1. 

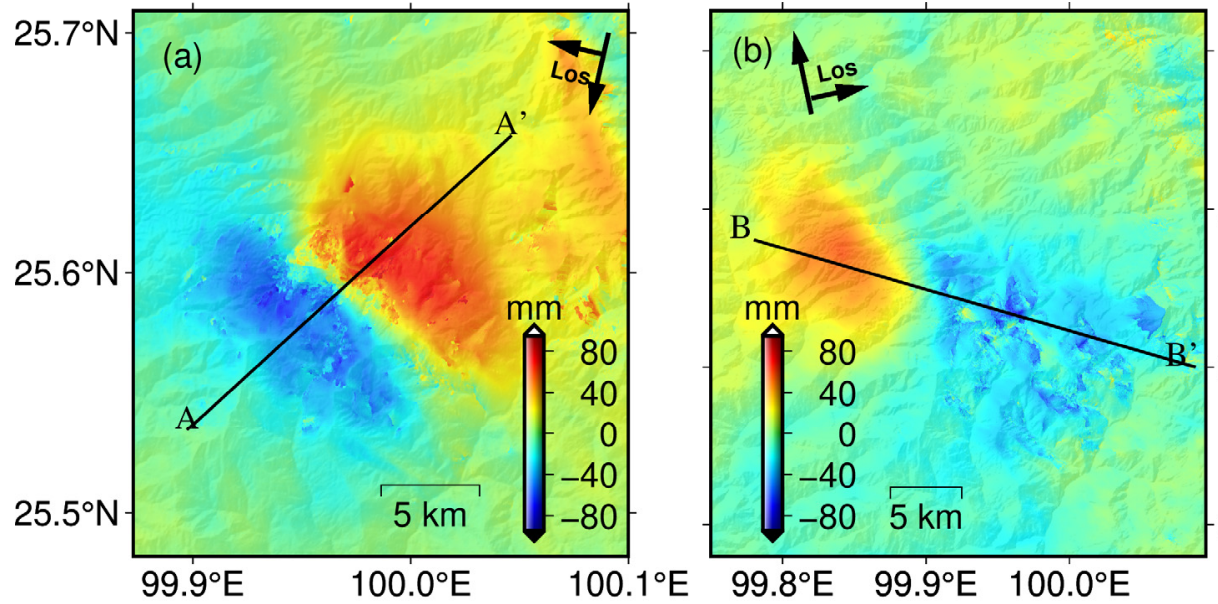

$25.8^{\circ} \mathrm{N}$
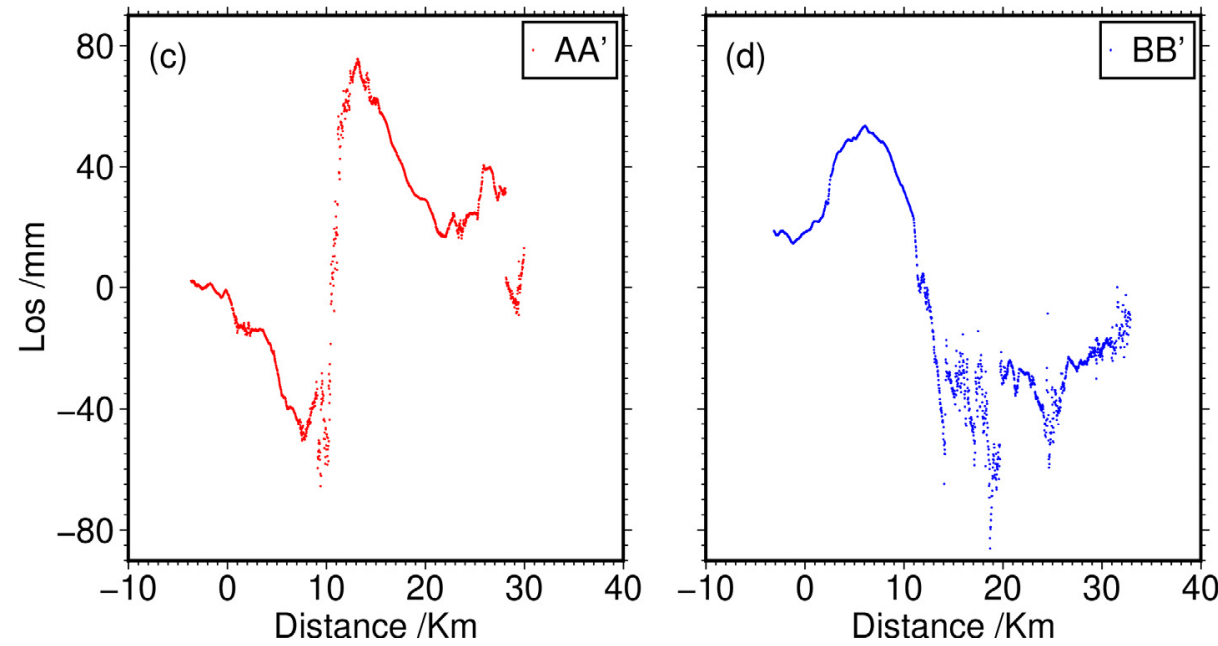

Figure 2. The coseismic deformation fields derived from the Sentinel-1 descending (a) and ascending (b) images. Cross-sections along A-A' (black line) and B-B' (black line) for the (c) descending and (d) ascending images.

Table 1. Sentinel-1A image used in this study.

\begin{tabular}{|c|c|c|c|c|c|c|c|c|}
\hline Orbit & Path & Frame & $\begin{array}{l}\text { Master } \\
\text { Image }\end{array}$ & $\begin{array}{l}\text { Slave } \\
\text { Image }\end{array}$ & $\begin{array}{l}\text { Polarization } \\
\text { Mode }\end{array}$ & Mode & $\begin{array}{c}\text { Incident } \\
\text { Angle }\left({ }^{\circ}\right)\end{array}$ & $\begin{array}{l}\text { Azimuth } \\
\left.\text { Angle ( }{ }^{\circ}\right)\end{array}$ \\
\hline Descending & 135 & 508 & 20210510 & 20210522 & VV & IW & 39.3550 & -167.5851 \\
\hline Ascending & 99 & 1265 & 20210520 & 20210601 & $V V$ & IV & 33.9425 & -12.4527 \\
\hline
\end{tabular}

We collected InSAR data from different periods in the same area to obtain the surface deformation caused by the earthquake [19-21]. To remove the influence of the topographic phase, we used $30 \mathrm{~m}$ resolution digital elevation data of the Space Shuttle Radar Topography Mission (SRTM), and precision orbit data of the European Space Agency (ESA), respectively [22]. In the distance and azimuth, a ratio of 5:1 is used for multi-view processing. The generated phase interferogram is unwrapped using the minimum cost flow (MCF) algorithm to obtain displacement data [23,24]. The phase change far away from the main deformation zone is ignored, and the influence of the track on the data processing is eliminated using a second order polynomial [25,26]. The Generic Atmospheric Correction Online Service for InSAR (GACOS) was then used to remove atmospheric errors and to obtain more accurate coseismic deformation fields $[27,28]$.

Figure $2 \mathrm{a}, \mathrm{b}$ shows the LOS deformation fields of the Yangbi earthquake obtained by Sentinel-1A data descending and ascending images. Two distinct areas with positive (red) 
and negative (blue) LOS displacement can be observed in both Figure $2 \mathrm{a}$ and in Figure $2 \mathrm{~b}$. They respectively represent 'approaching' and 'away-from-the-satellite' in the line-of-sight direction. The shape of the deformation fields, shown in red and blue, are both an ellipse. By observing their long axis direction, it can be inferred that the fault rupture strike is NW-SE. Figure $2 \mathrm{c}$ shows that the maximum and minimum LOS values on the $\mathrm{AA}^{\prime}$ section are $79 \mathrm{~mm}$ and $-76 \mathrm{~mm}$, respectively. Figure $2 \mathrm{~d}$ shows that the maximum and minimum LOS values on the $\mathrm{BB}^{\prime}$ section are $53 \mathrm{~mm}$ and $-83 \mathrm{~mm}$, respectively.

\subsection{Uniform Slip Model}

Due to a large amount of InSAR coseismic deformation field data, each interferometric image contains $10^{6}$ data points, and there is a strong correlation among pixels; using all pixels will result in calculation difficulties [29]. To solve this problem and improve the speed and accuracy of InSAR data inversion, previous studies have proposed methods such as uniform sampling and quadtree sampling [30]. In this study, the quadtree sampling method is used to process InSAR data. Considering the physical spatial correlation of InSAR deformation monitoring data, we set up the covariance function, and determined the quadtree quadrant decomposition threshold according to the covariance function. The quadtree threshold we calculated was 0.0082. The far-field sampling of the deformation field yielded a sparse result, and the near-field sampling result is dense; this approach effectively reduces the effect of the large-error area on the overall deformation result. Overall, the spatial characteristics of the original deformation field are preserved to the greatest extent possible (Figure 3).
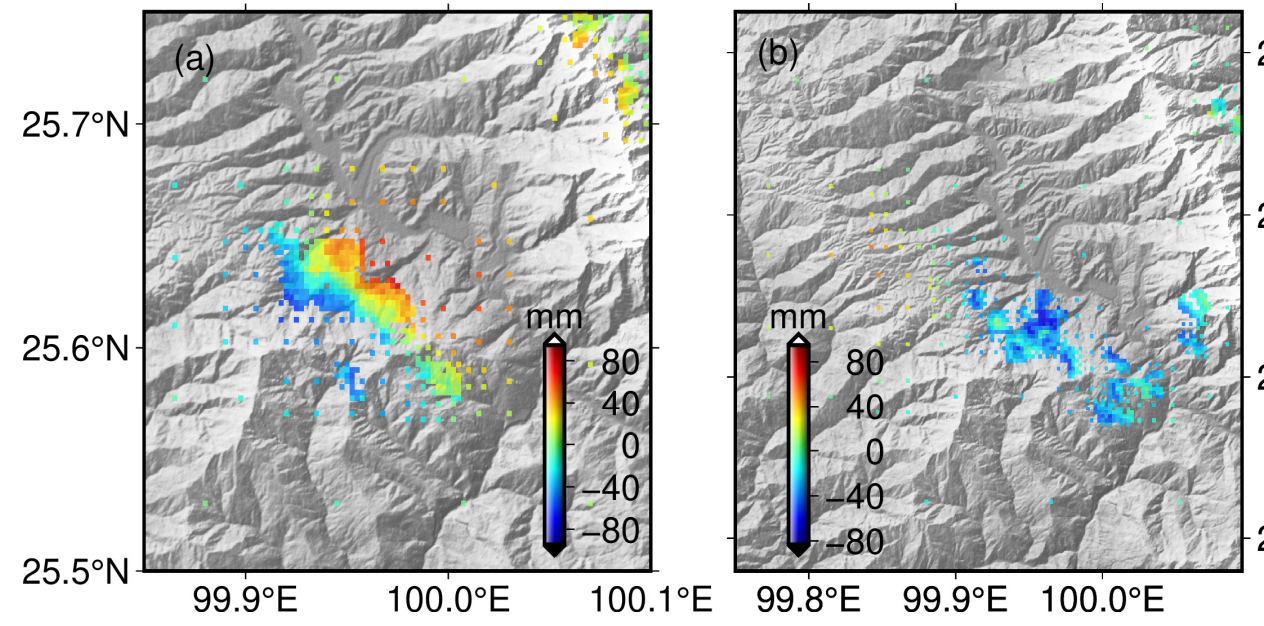

$25.8^{\circ} \mathrm{N}$

Figure 3. Quadtree sampling results of the coseismic deformation fields for (a) descending with 3003 observation points, and (b) ascending with 3390 observation points.

Based on previous studies on the seismogenic faults of historical earthquakes in the Yangbi area of Dali, in recent years, there have been many strong earthquakes in the central and southern segments of the Weixi-Weishan fault [31,32]. According to these earthquake events, we can obtain the approximate geometric structure of the fault, i.e., the location, length, strike angle, dip angle, and depth. Based on these studies, we set the slip of the seismogenic fault of the Yanghe Ms 6.4 earthquake as a simple rectangular uniform slip [33]. Therefore, we use the Geodetic Bayesian Inversion Software (GBIS) [34] to study the fault parameters of the Yangbi earthquake in 2021. The fault parameters required in the algorithm are shown in Table 2. To find the optimal parameters and their uncertainties, the nine parameters were determined by minimizing the squared misfits between the observed and predicted LOS deformations using the downhill simplex method and Monte Carlo simulations [35]. The threshold value of the root determines the output of the parameter means square error. Finally, the inversion results of 1 million iterations are shown in 
Table 2. The inverted fault length, width, strike angle, and dip provide parameters for the distributed slip model.

Table 2. GBIS inversion of the Yangbi earthquake parameters and their standard deviations.

\begin{tabular}{ccc}
\hline Parameter (Unit) & Intervals of Parameters & Yangbi Earthquake \\
\hline Length $(\mathrm{km})$ & $(1-20 \mathrm{~km})$ & $10.9 \pm 2$ \\
Width $(\mathrm{km})$ & $(1-20 \mathrm{~km})$ & $1.9 \pm 0.3$ \\
Depth $(\mathrm{km})$ & $(1-12 \mathrm{~km})$ & $7.0 \pm 0.05$ \\
Strike $\left(^{\circ}\right)$ & $\left(0-360^{\circ}\right)$ & $316 \pm 2.89$ \\
Dip $\left(^{\circ}\right)$ & $\left(0-90^{\circ}\right)$ & $86 \pm 3.41$ \\
Strike slip $(\mathrm{m})$ & $(-10-10 \mathrm{~m})$ & $-0.31 \pm 0.03$ \\
Dip slip $(\mathrm{m})$ & $(-10-10 \mathrm{~m})$ & $1.97 \pm 0.01$ \\
$X(\mathrm{~km})$ & $(0-5 \mathrm{~km})$ & $1.5 \pm 0.7$ \\
$Y(\mathrm{~km})$ & $(-6-6 \mathrm{~km})$ & $-2.7 \pm 0.6$ \\
\hline
\end{tabular}

Figure 4 shows the observed (Figure 4a,d) and simulated results of the uniform slip model (Figure $4 \mathrm{~b}, \mathrm{e}$ ), as well as their residuals (Figure 4c,f). Comparing Figure 4a,b, it can be seen that the deformation field of the Yangbi earthquake was simulated well by the GBIS inversion code. It can be seen from Figure $4 \mathrm{c}$ that the residual of the fit is small. The maximum residuals of Figure $4 \mathrm{c}$ are less than $\pm 30 \mathrm{~mm}$ in the near field areas of the earthquake. Although the residual error in Figure $4 \mathrm{f}$ is large, it is mainly because the ascending track data obtained after the earthquake had been 10 days from the time of the earthquake, which caused the coseismic deformation and the post-earthquake deformation of the crust to be mixed together. Based on the results of Figure $4 a-f$, we accept this inversion result (Table 2) as representing the best fit for the rupture model.
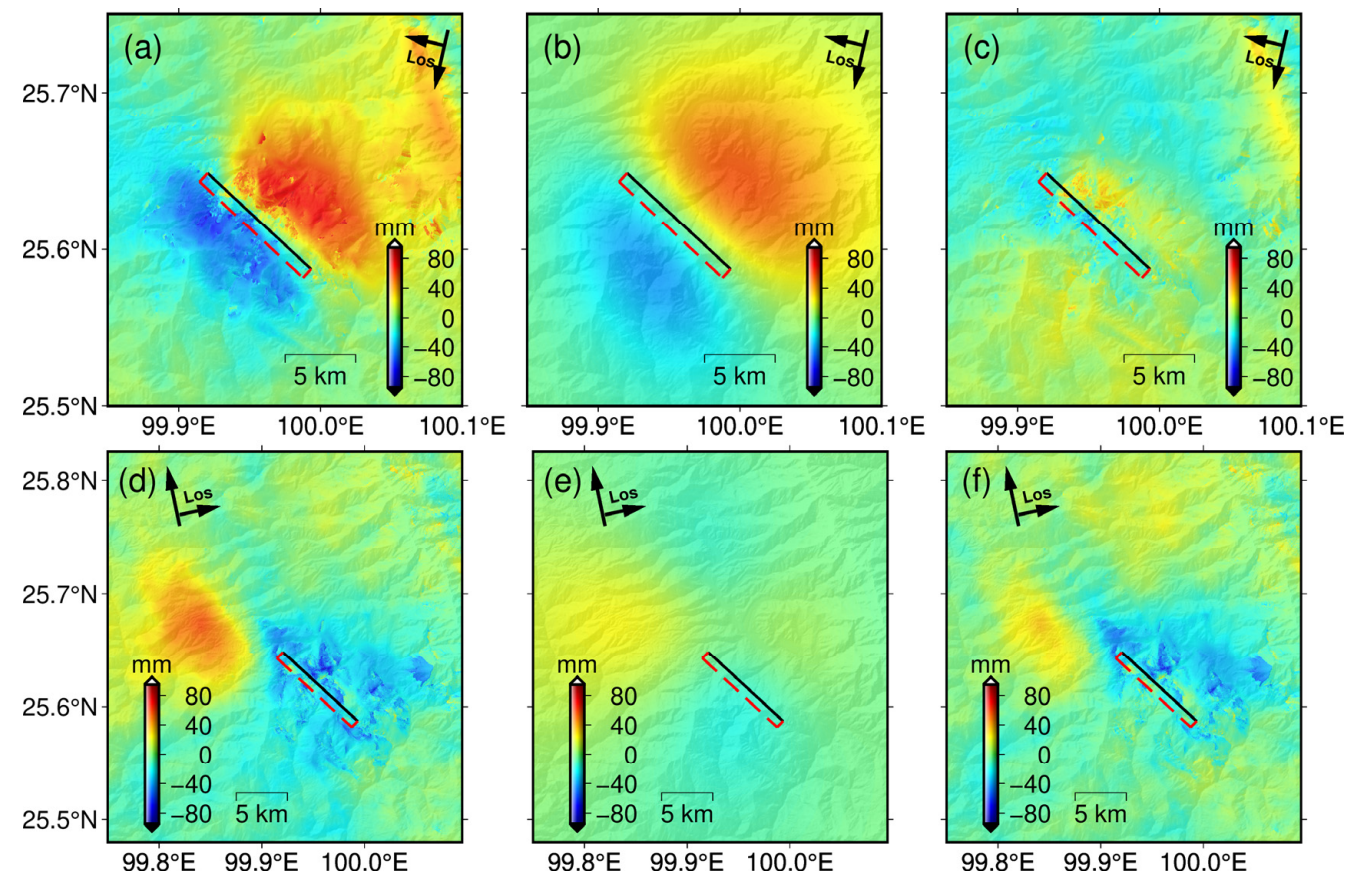

Figure 4. Inversion results of the uniform slip inversion model for the Yangbi earthquake; (a,d) are the observed coseismic interferograms of the descending and ascending tracks, respectively; (b,e) are corresponding modeled data; $(\mathbf{c}, \mathbf{f})$ are the residuals. In $(\mathbf{a}-\mathbf{f})$, thick black line depicts the fault surface trace of the uniform slip model while dashed red line shows the surface projection of the rupture fault plane. 


\subsection{Distributed Slip Model}

With the abundance of observational data, it has emerged that the inhomogeneity of the earth's medium has a certain impact on coseismic deformation. There is a gap between the depth of the fault retrieved by using the uniform dislocation model and the actual fault in the semi-infinite space, and the slip amount retrieved is also too large. To solve this problem, the steepest descent method (SDM) of the stratified medium model was used, which took into account the stratification of the earth and obtained many applications [36].

The strike, dip, and size of sub-faults in this algorithm can be obtained according to uniform dislocation inversion or other methods. Based on the inversion results of GBIS and the distribution of aftershocks in the area recorded by the China Seismic Network (Figure 5), we present estimates of the rupture length, dip angle, and other parameters of the fault. Based on that information, we determined the rupture length to be $18 \mathrm{~km}$, and the width along with the dip to $20 \mathrm{~km}$. The fault plane is divided into $2 \mathrm{~km} \times 2 \mathrm{~km}$ fault patches. The three-dimensional distribution of the seismogenic fault is shown in Figure 5.

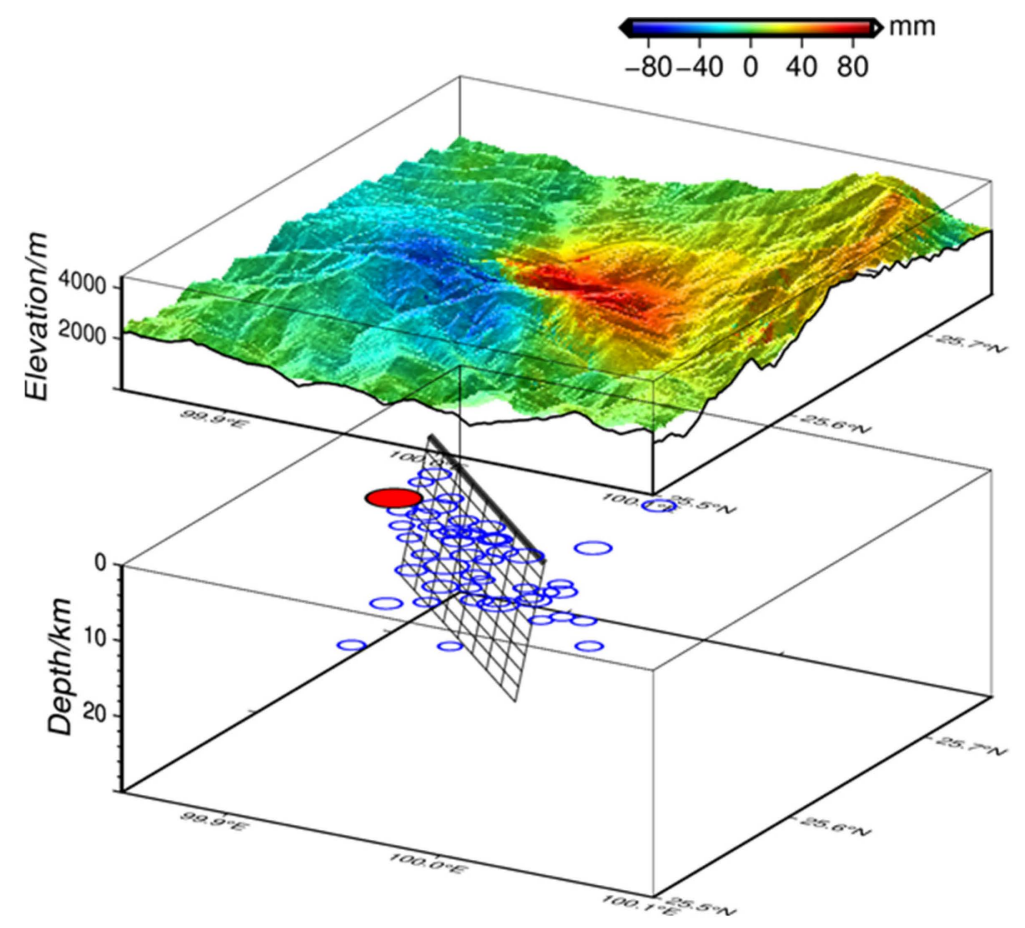

Figure 5. Three-dimensional location of fault. Upper: Coseismic deformation field from Sentinel-1 (descending track) superposed on the topography map. Lower: Fault model for inversion of coseimic slip distribution. Blue open circles represent aftershocks. The circle size is proportional to magnitude. Red solid circle represents the mainshock.

To ensure the stability of the inversion, the stress and dislocation should be smoothly constrained in the inversion. The SDM considers the constraint conditions for the smoothing of the stress drop on the fault plane and determines the smoothing factor by constraining the range of the stress drop to be widely used [37,38]. Figure 6 shows the roughness and relative fitting residual positions corresponding to 29 smoothing factors used in this paper. The smoothing factor determined by the relationship curve is 0.025 . In addition, the stratification of the crust is extracted from the CRUST1.0 model [39], which divides the world into a $1^{\circ} \times 1^{\circ}$ grid. 


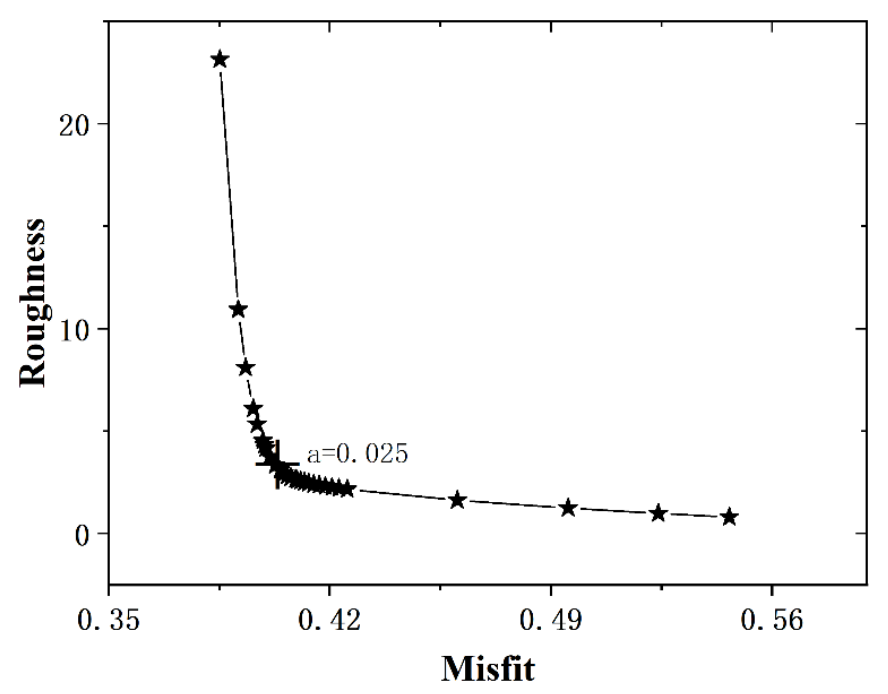

Figure 6. Smoothing factor determination graph (indicated by letter a).

Figure 7 shows that the deformation field of the Yangbi earthquake corresponds with the inversion of the fault plane. Comparing Figures $7 \mathrm{c}$ and $4 \mathrm{c}$, it can be seen that the result of Figure 7 is more in line with the actual seismic deformation. The maximum residuals of Figure $7 \mathrm{c}$ are less than $\pm 15 \mathrm{~mm}$ in the near field areas of the earthquake. Although the residual error in Figure $7 \mathrm{f}$ is still large, it has been well improved. To sum up, the inversion result of the distribution slip model is better. The fault rupture of the Yangbi earthquake can be seen from the three-dimensional deformation map of the seismogenic fault of the Yangbi earthquake (Figure $8 \mathrm{~b}$ ). On the fault plane, the rupture is mainly concentrated at a depth of 3 to $13 \mathrm{~km}$, and the maximum slip $61 \mathrm{~cm}$ occurs at a depth of $6.98 \mathrm{~km}$. This is consistent with the distribution of aftershocks in the Yangbi area. It also proved the validity of this inversion. It can be seen from Figure $8 \mathrm{a}$ that the fault activity has the characteristics of the right-lateral strike slip. Lastly, the Yangbi seismic fault obtained by our inversion has a strike and dip of $315^{\circ}$ and $86^{\circ}$, respectively. The geodetic moment based on the distributed slip is $1.818 \times 10^{18} \mathrm{~N} \cdot \mathrm{m}$, corresponding to Mw 6.14. 

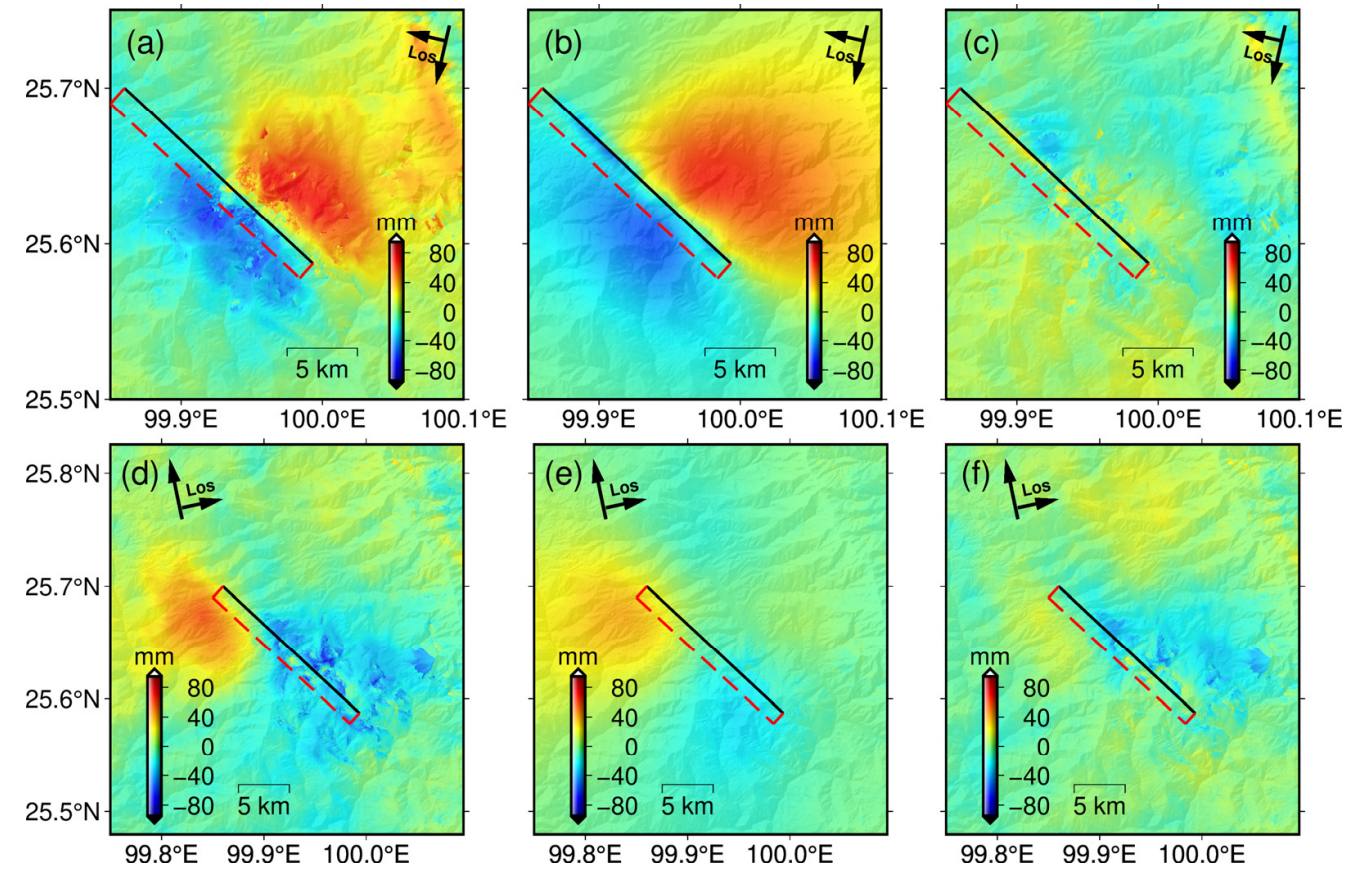

Figure 7. Inversion results of the distribution slip inversion model for the Yangbi earthquake; (a,d) are the observed coseismic interferograms of the descending and ascending tracks, respectively; (b,e) are corresponding modeled data; $(\mathbf{c}, \mathbf{f})$ are the residuals. In (a-f), the thick black line depicts the fault surface trace of the distributed slip model, while the dashed red line shows the surface projection of the rupture fault plane.

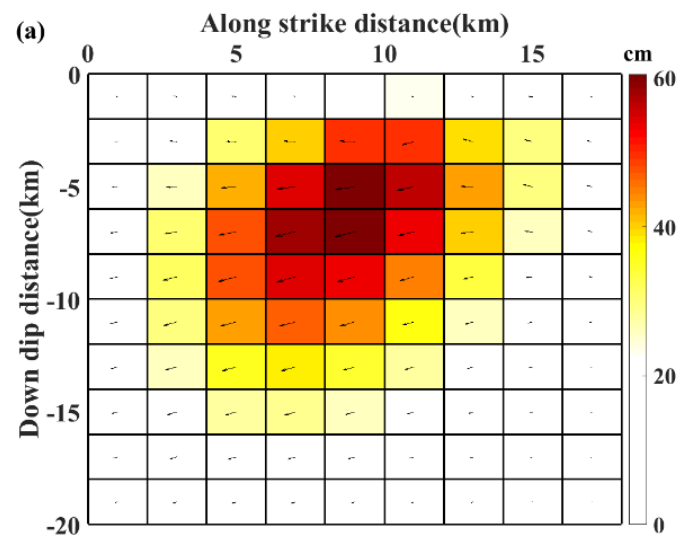

(b)

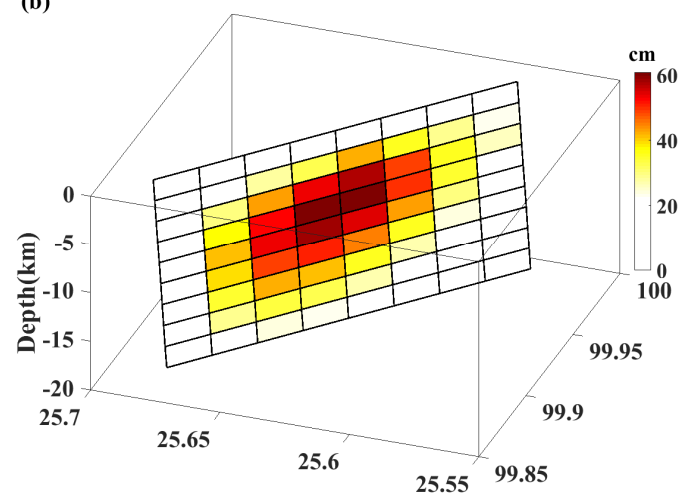

(c)

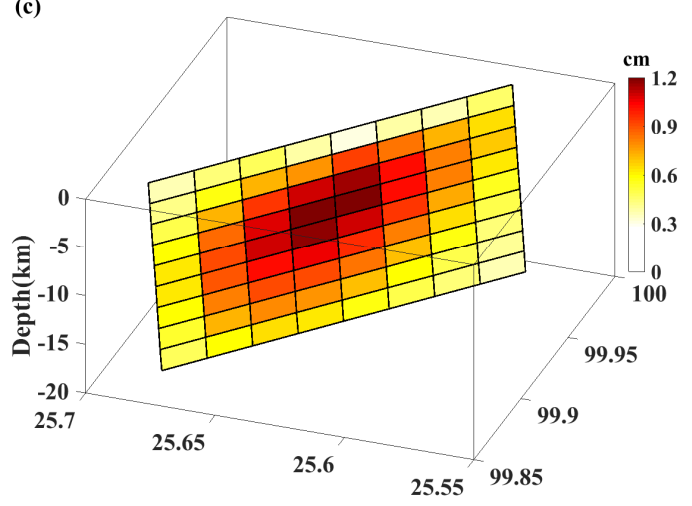

Figure 8. (a) Two-dimensional results of fault plane slip; (b) Three-dimensional display of fault slip; (c) The Monte Carlo estimation of fault slip with $1 \sigma$ uncertainty. 


\section{Discussion}

\subsection{Analysis of the Yangbi Earthquake Inversion Results}

As can be seen from the results of Figure 8, the seismogenic fault of the Yangbi earthquake did not rupture to the surface, and the seismogenic fault of the Yangbi earthquake may be caused by a blind fault. It can be seen in Table 3 that the best strike angle and dip angle of the seismogenic fault obtained by the inversion in this paper are consistent with the results of other institutions and scholars (Table 3).

Table 3. Comparison of focal parameters of the 2021 Yangbi Ms6.4 earthquake given by different agencies.

\begin{tabular}{|c|c|c|c|c|}
\hline \multirow{2}{*}{ Source } & \multicolumn{2}{|c|}{ Fault Plane } & \multirow{2}{*}{ Difference in Strike $\left({ }^{\circ}\right)$} & \multirow{2}{*}{ Difference in Dip $\left(^{\circ}\right)$} \\
\hline & Strike $\left(^{\circ}\right)$ & $\operatorname{Dip}\left({ }^{\circ}\right)$ & & \\
\hline USGS & 135 & 82.00 & 0 & -4 \\
\hline GCMT & 315 & 86.00 & 0 & 0 \\
\hline Yu et al. [40] & 135 & 83.47 & 0 & -2.53 \\
\hline This study & 315 & 86.00 & & \\
\hline
\end{tabular}

In terms of fault geometry parameters, many NW trending linear structures can be found through analysis of optical satellite images associated with the high mountains and numerous faults in the earthquake area, but the identification of seismogenic structures is extremely difficult [41,42]. In this study, the distribution of aftershocks published by the China National Seismic Network, and focal mechanism solutions published by local and international seismological research institutions through geophysical methods, are summarized. We can get the rough geometry of the fault and set the seismogenic fault of the Yangbi earthquake as a single fault plane. According to the inversion results of uniform and distributed dislocations (Figures 4 and 7), it can be seen that the setting of fault parameters is reasonable. From the results of slip distribution model, the rupture of the fault plane in this study is mainly concentrated at a depth of 3-13 along the dip, which is consistent with the position of the aftershock depth distribution. The rupture of the fault did not extend to the surface. Based on the above research, we think that the Yangbi earthquake was caused by a blind fault in the NW-SE trend on the west side parallel to the Weixi-Weishan fault, which has right-lateral strike-slip characteristics.

\subsection{Stress Loading Caused by the Yangbi Earthquake}

As a release after the regional stress is highly concentrated, an earthquake will have a certain impact on the occurrence of aftershocks in the stress field nearby [43]. The change of Coulomb stress will promote the occurrence of aftershocks after the mainshock [44]. The seismic data obtained from the China Seismological Network in the Yangbi area show that before the Yangbi Ms 6.4 earthquake, a group of small earthquakes of magnitude three and four occurred in the area. This group of small earthquakes is closely related to the magnitude 6.4 earthquake, so it is called the foreshock of the magnitude 6.4 earthquake. A series of earthquakes occurred after the magnitude 6.4 earthquake. Therefore, the Yangbi Ms 6.4 earthquake sequence is of "foreshock-mainshock-aftershock type".

The seismogenic fault of the Yangbi earthquake has become the main research object, and the influence of its stress is further analyzed. Regarding the choice of friction coefficient, scholars generally believe its value is 0.4 [45]. We chose 0.4 and 0.7 for the friction coefficient $\mu$. It can be seen from Figure 9 that the different values of the friction coefficient will not change significantly in the spatial distribution. There is a slight difference in amplitude. We discussed the stress loading at depths of $8 \mathrm{~km}, 12 \mathrm{~km}$, and $16 \mathrm{~km}$. When the friction coefficient is set to 0.4 , the CFS results at different depths mainly show that significant changes only occur near the epicenter. Figure 9 shows the loading and unloading effects of the Yangbi earthquake on the static Coulomb stress field at depths of $8 \mathrm{~km}, 12 \mathrm{~km}$, and $16 \mathrm{~km}$. The figure shows that as the depth increases, the expanse of the area where the 
Coulomb stress increases in the Yangbi earthquake decreases, and its value decreases, and the number of aftershocks at a depth of $8 \mathrm{~km}$ is the largest.
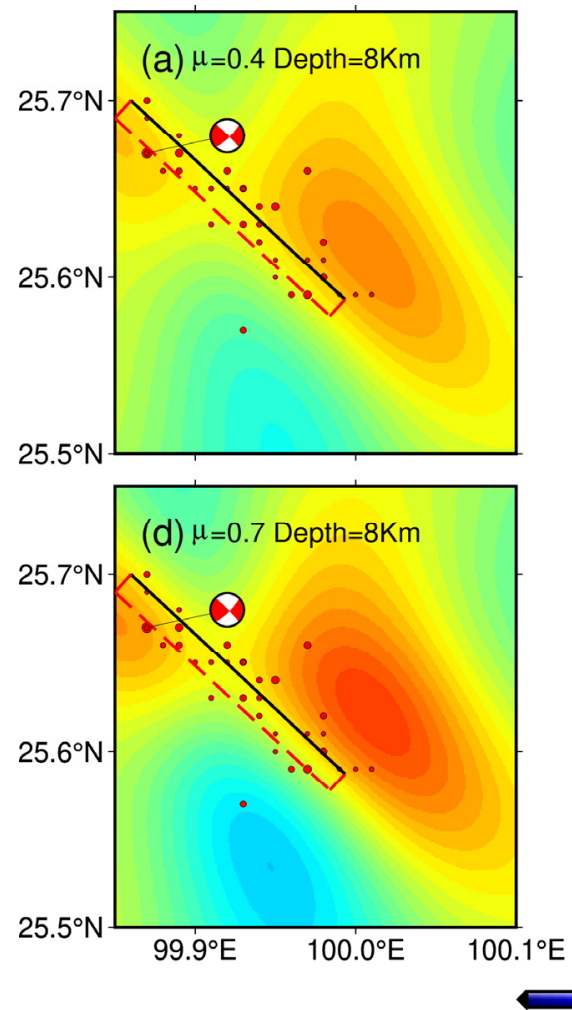
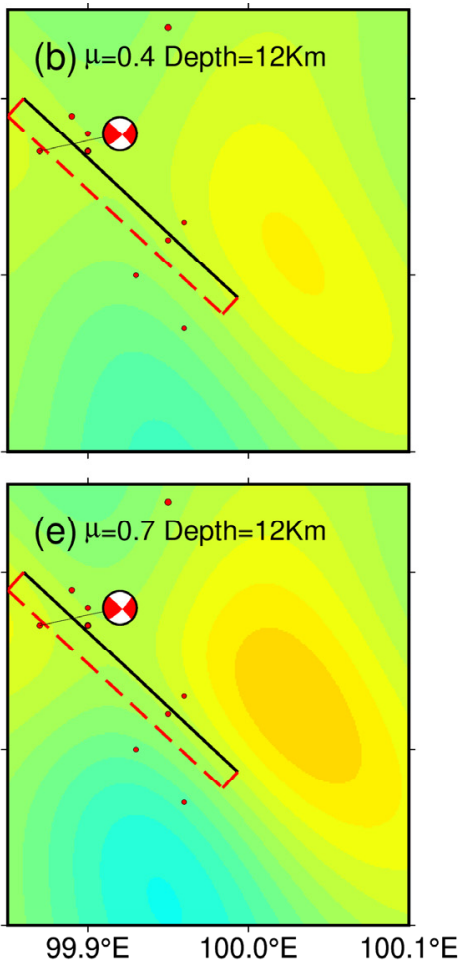

(f) $\mu=0.7$ Depth $=16 \mathrm{Km}$
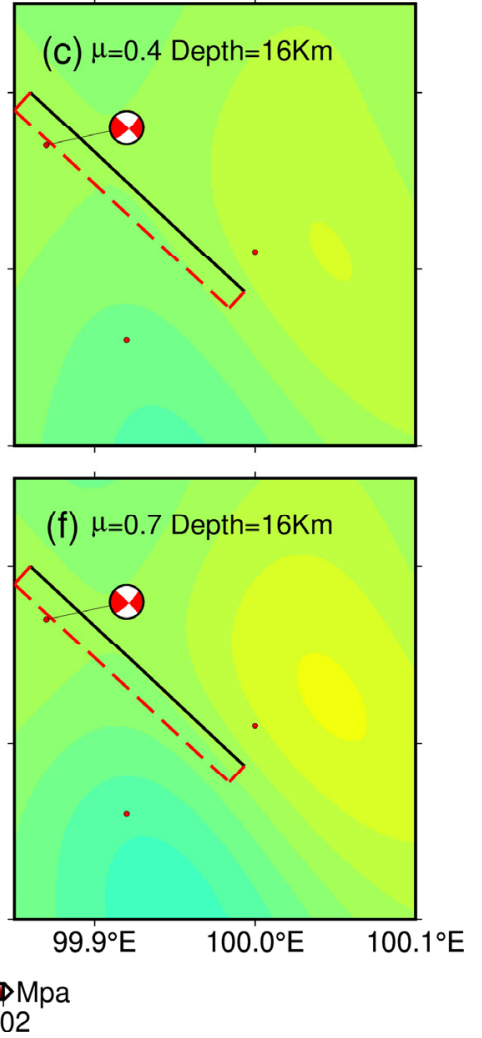

Figure 9. Influence on aftershocks of the static Coulomb stress change caused by the $2021 \mathrm{Ms} 6.4$ earthquake. The red circles (a-f) indicate aftershocks. (a,d) show the aftershocks at depths $0 \sim 8 \mathrm{~km}$; (b,e) show the aftershocks at depths 8 13 km; (c,f) show the aftershocks deeper than $13 \mathrm{~km}$. The red beach ball diagram and rectangular box represent the source and the receiver fault, respectively.

The earthquake will change the fault stress field around the earthquake. After the Yangbi earthquake, the change of Coulomb stress of main faults such as the Weixi-Weishan fault, the north section of the Red River fault, and the Lancang River fault zone is not clear. According to the aftershock distribution and the main distribution position of sliding obtained from inversion, the change of Coulomb stress at $8 \mathrm{~km}$ of each fault is calculated in this paper (Figure 10).

It can be seen from Figure 10 that after the Yangbi earthquake, most of the active faults in this area did not trigger the threshold of $0.1 \times 10^{5} \mathrm{~Pa}$ for the Coulomb stress increment. The relatively obvious increase in the southeast section of the Weixi-Weishan Fault should raise concern about the seismic hazard of the fault. 


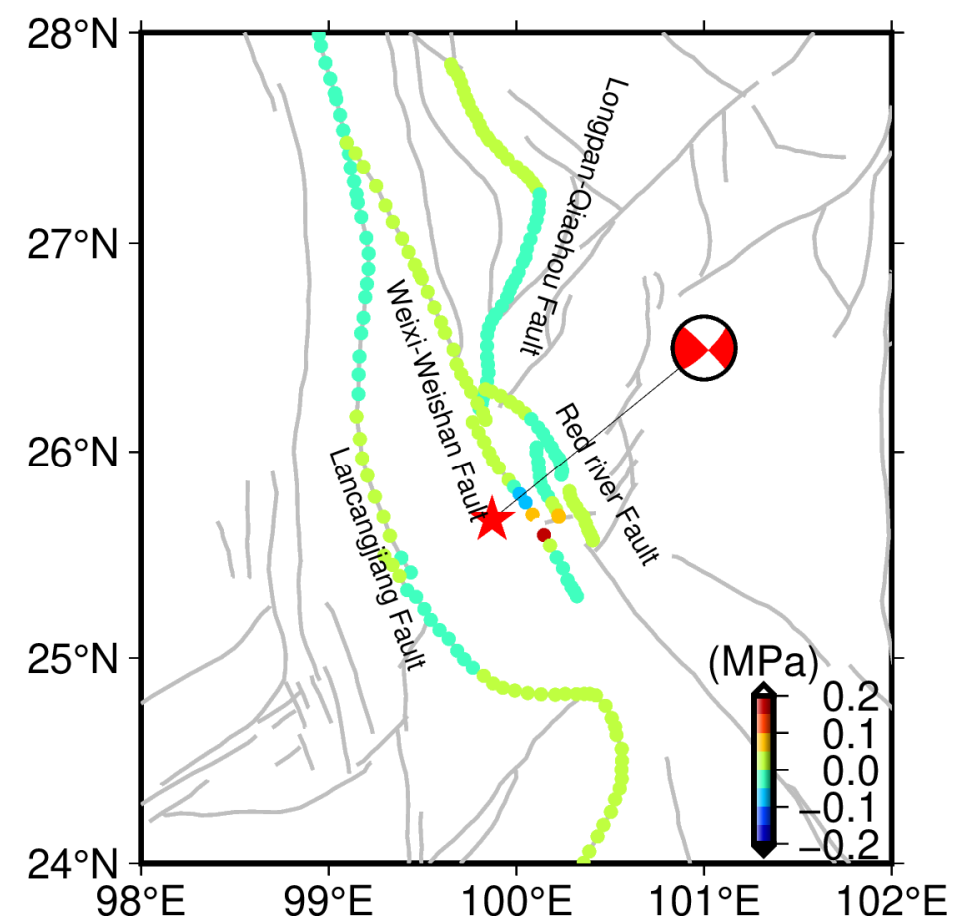

Figure 10. The static Coulomb stress changes of surrounding large faults caused by the Yangbi earthquake.

\section{Conclusions}

In this study, the focal mechanism of the Yangbi earthquake is inversed by using Sentinel-1A data. First, the coseismic LOS deformation fields of both the descending and ascending tracks are obtained. Secondly, we used a two-step method to carry out uniform slip distribution inversion and distributed slip inversion, respectively. Finally, we analyzed the stress loading effect of the Yangbi earthquake. The results show that the moment magnitude of the Yangbi earthquake was Mw 6.14. The slip mainly occurred at depths of 3-13 km, with a maximum slip of approximately $61 \mathrm{~cm}$ at a depth of $6.98 \mathrm{~km}$. The Yangbi earthquake was triggered by a blind fault in the NW-SE in the west parallel to the Weixi-Weishan fault, and its seismogenic fault exhibits strike-slip displacement. A large number of aftershocks were distributed in the area where the Coulomb force increased. The occurrence of this earthquake also caused a significant increase in the Coulomb stress in the southeastern section of the Weixi-Weishan fault, which deserves further attention.

It can be seen from Figures $4 \mathrm{f}$ and $9 \mathrm{f}$ that the post-seismic deformation fields are also obvious, and we need to further analyze these. Since this paper only studies the coseismic mechanism of Yangbi based on a single data source, the subsequent research should also be combined with the data of GNSS and relocated aftershocks.

Author Contributions: All authors participated in editing and reviewing the manuscript. B.Z. implemented the methodology, analyzed the InSAR data, produced the results, and wrote the original paper. Y.H. and M.P. implemented related experiments. G.X. and Z.L. supervised the research and revised the manuscript. X.F. proofread and revised the manuscript. All authors have read and agreed to the published version of the manuscript.

Funding: This study was supported by the Shenzhen Science and Technology Program (Grant No. KQTD20180410161218820) and Guangdong Basic and Applied Basic Research Foundation (2021A1515012600).

Institutional Review Board Statement: We choose to exclude this statement because the study did not involve humans or animals. 
Informed Consent Statement: We choose to exclude this statement because the study did not involve humans.

Data Availability Statement: Authors are grateful to the European Space Agency (ESA) for providing the Sentinel-1A SAR data and the precise orbit information free of charge.

Acknowledgments: Some figures were prepared using the public domain Generic Mapping Tools GMT [46]. In the end, the authors like to thank the anonymous reviewers for their efforts and constructive comments to improve the quality of this paper.

Conflicts of Interest: The authors declare no conflict of interest.

\section{References}

1. Li, J.; Jiang, J.Z.; Yang, J.Q. Microseismic detection and relocation of the 2017 MS4.8 and MS5.1 Yangbi earthquake sequence, Yunnan. Acta Seismol. Sin. 2020, 42, 527-542, (In Chinese with English abstract).

2. Pan, R.; Jiang, J.Z.; Fu, H.; Li, J. Focal mechanism solution and focal depth determination of the m_s5.1 and m_s4.8 earthquakes in Yangbi, Yunnan. J. Seismol. Res. (In Chinese with English abstract). 2019, 42, 338-348.

3. Xu, C.; Liu, Y.; Wen, Y.; Wang, R. Coseismic Slip Distribution of the $2008 \mathrm{Mw} 7.9$ Wenchuan Earthquake from Joint Inversion of GPS and InSAR Data. Bull. Seism. Soc. Am. 2010, 100, 2736-2749. [CrossRef]

4. Atzori, S.; Hunstad, I.; Chini, M.; Salvi, S.; Tolomei, C.; Bignami, C.; Stramondo, S.; Trasatti, E.; Antonioli, A.; Boschi, E. Finite fault inversion of DInSAR coseismic displacement of the 2009 L'Aquila earthquake (central Italy). Geophys. Res. Lett. 2009, 36, L15305. [CrossRef]

5. Hayes, G.P.; Briggs, R.; Sladen, A.; Fielding, E.; Prentice, C.; Hudnut, K.; Mann, P.; Taylor, F.W.; Crone, A.J.; Gold, R.; et al. Complex rupture during the 12 January 2010 Haiti earthquake. Nat. Geosci. 2010, 3, 800-805. [CrossRef]

6. Pollitz, F.F.; Brooks, B.; Tong, X.; Bevis, M.G.; Foster, J.; Bürgmann, R.; Smalley, R.; Vigny, C.; Socquet, A.; Ruegg, J.; et al. Coseismic slip distribution of the February 27, 2010 Mw 8.8 Maule, Chile earthquake. Geophys. Res. Lett. 2011, 38. [CrossRef]

7. Barnhart, W.D.; Willis, M.J.; Lohman, R.B.; Melkonian, A.K. InSAR and Optical Constraints on Fault Slip during the 2010-2011 New Zealand Earthquake Sequence. Seism. Res. Lett. 2011, 82, 815-823. [CrossRef]

8. Elliott, J.; Copley, A.; Holley, R.; Scharer, K.; Parsons, B. The 2011 Mw 7.1 Van (Eastern Turkey) earthquake. J. Geophys. Res. Solid Earth 2013, 118, 1619-1637. [CrossRef]

9. Feng, G.; Ding, X.; Li, Z.; Mi, J.; Zhang, L.; Omura, M. Calibration of an InSAR-Derived Coseimic Deformation Map Associated With the 2011 Mw-9.0 Tohoku-Oki Earthquake. IEEE Geosci. Remote. Sens. Lett. 2012, 9, 302-306. [CrossRef]

10. Wang, K.; Fialko, Y. Slip model of the $2015 \mathrm{M} \mathrm{w} 7.8$ Gorkha (Nepal) earthquake from inversions of ALOS-2 and GPS data. Geophys. Res. Lett. 2015, 42, 7452-7458. [CrossRef]

11. Tapponnier, P.; Zhiqin, X.; Roger, F.; Meyer, B.; Arnaud, N.; Wittlinger, G.; Jingsui, Y. Oblique Stepwise Rise and Growth of the Tibet Plateau. Science 2001, 294, 1671-1677. [CrossRef] [PubMed]

12. Wang, Y.; Li, J.; Chen, H.; Zou, Z. The time process of post-earthquake recovery: The Yao'an earthquake in China. Disasters 2014, 38, 774-789. [CrossRef] [PubMed]

13. Yao, H.J.; van der Hilst, R.D.; Montagner, J.-P. Heterogeneity and anisotropy of the litho-sphere of SE Tibet from surface wave array tomography. J. Geophys. Res. 2010, 115, B12307. [CrossRef]

14. Xu, X.; Ding, Z.; Shi, D.; Li, X. Receiver function analysis of crustal structure beneath the eastern Tibetan plateau. J. Asian Earth Sci. 2013, 73, 121-127. [CrossRef]

15. Su, Y.J.; Qin, J.Z. Strong Earthquake Activity and Relation to Regional Neotectonic Movement in Sichuan-Yunnan Region. Earthq. Res. China 2001, 17, 24-34, (In Chinese with English abstract).

16. Allen, C.R.; Gillespie, A.R.; Yuan, H.; Sieh, K.E.; Buchun, Z.; Chengnan, Z. Red River and associated faults, Yunnan Province, China: Quaternary geology, slip rates, and seismic hazard. Geol. Soc. Am. Bull. 1984, 95, 686. [CrossRef]

17. Tapponnier, P.; Lacassin, R.; Leloup, P.H.; Schärer, U.; Dalai, Z.; Haiwei, W.; Jiayou, Z. The Ailao Shan/Red River metamorphic belt: Tertiary left-lateral shear between Indochina and South China. Nature 1990, 343, 431-437. [CrossRef]

18. Zhang, P.Z.; Gan, W.J.; Shen, Z.K. A coupling model of rigid-block movement and continuous deformation: Patterns of the present-day deformation of China's continent and its vicinity. Acta Geol. Sin. 2005, 79, 748-756.

19. Massonnet, D.; Feigl, K. Radar interferometry and its application to changes in the Earth's surface. Rev. Geophys. 1998, 36, 441-500. [CrossRef]

20. Rosen, P.A.; Hensley, S.; Joughin, I.R.; Li, F.K.; Madsen, S.N.; Rodriguez, E.; Goldstein, R.M. Synthetic aperture radar interferometry. Proc. IEEE 2000, 88, 333-380. [CrossRef]

21. Werner, C.; Wegmüller, U.; Strozzi, T.; Wiesmann, A. GAMMA SAR and interferometric processing software. In Proceedings of the ERS-Envisat Symposium, Gothenburg, Sweden, 16-20 October 2000.

22. Farr, T.G.; Rosen, P.A.; Caro, E.; Crippen, R.; Duren, R.; Hensley, S.; Kobrick, M.; Paller, M.; Rodriguez, E.; Roth, L.; et al. The Shuttle Radar Topography Mission. Rev. Geophys. 2007, 45. [CrossRef] 
23. Costantini, M.; Rosen, P.A. A generalized phase unwrapping approach for sparse data. In Proceedings of the IEEE 1999 International Geoscience and Remote Sensing Symposium. IGARSS'99 (Cat. No.99CH36293), Hamburg, Germany, 28 June-2 July 1999; pp. 267-269. [CrossRef]

24. Qu, W.; Liu, B.; Zhang, Q.; Gao, Y.; Chen, H.; Wang, Q.; Hao, M. Sentinel-1 InSAR observations of co- and post-seismic deformation mechanisms of the 2016 Mw 5.9 Menyuan Earthquake, Northwestern China. Adv. Space Res. 2021, 68, 1301-1317. [CrossRef]

25. Rosen, P.A.; Hensley, S.; Zebker, H.A.; Webb, F.H.; Fielding, E. Surface deformation and coherence measurements of Kilauea Volcano, Hawaii, from SIR-C radar interferometry. J. Geophys. Res. Space Phys. 1996, 101, 23109-23125. [CrossRef]

26. Lu, Z.; Dzurisin, D. InSAR Imaging of Aleutian Volcanoes; Springer: Berlin/Heidelberg, Germany, 2014; pp. 87-345. [CrossRef]

27. Yu, C.; Li, Z.; Penna, N.T.; Crippa, P. Generic Atmospheric Correction Model for Interferometric Synthetic Aperture Radar Observations. J. Geophys. Res. Solid Earth 2018, 123, 9202-9222. [CrossRef]

28. Li, Z.; Muller, J.-P.; Cross, P.; Fielding, E. Interferometric synthetic aperture radar (InSAR) atmospheric correction: GPS, Moderate Resolution Imaging Spectroradiometer (MODIS), and InSAR integration. J. Geophys. Res. Space Phys. 2005, 110. [CrossRef]

29. Luo, X.W.; Sun, J.B.; Shen, Z.K.; Yo, F. Co-seismic slip distribution of 2010 Darfield, New Zealand Mw7.1 earthquake inverted using InSAR measurements. Chin. J. Geophys. 2013, 56, 117-128, (In Chinese with English abstract).

30. Jonsson, S. Fault Slip Distribution of the 1999 Mw 7.1 Hector Mine, California, Earthquake, Estimated from Satellite Radar and GPS Measurements. Bull. Seism. Soc. Am. 2002, 92, 1377-1389. [CrossRef]

31. An, X.W.; Chang, Z.F.; Chen, Y.J.; Mao, X.J.; Zhuang, R.X. Quaternary Active Faults in Yunnan Area and Distribution Map of the Quaternary Active Faults in Yunnan Area; Seismology Press: Beijing, China, 2018; pp. 57-262.

32. Chang, Z.F.; Zhang, Y.F.; Chang, H. New Discovery of Holocene Activity along the Weixi-Qiaohou Fault in Southeastern Margin of the Tibetan Plateau and its Neotectonic Significance. Acta Geol. Sin. 2018, 92, 2464-2465, (In Chinese with English abstract).

33. Okada, Y. Surface deformation due to shear and tensile faults in a half-space. Bull. Seismol. Soc. Am. 1985, 75, 1135-1154. [CrossRef]

34. Bagnardi, M.; Hooper, A. Inversion of Surface Deformation Data for Rapid Estimates of Source Parameters and Uncertainties: A Bayesian Approach. Geochem. Geophys. Geosystems 2018, 19, 2194-2211. [CrossRef]

35. Press, W.; Teukolsky, S.; Vetterling, W.; Flannery, B. Numerical Recipes in C, the Art of Scientific Computing; Cambridge University Press: New York, NY, USA, 1992; p. 994. [CrossRef]

36. Wang, R.; Diao, F.; Hoechner, A. SDM-A geodetic inversion code incorporating with layered crust structure and curved fault geometry. In Proceedings of the EGU General Assembly 2013, Vienna, Austria, 7-12 April 2013.

37. Tu, H.-W.; Wang, R.-J.; Diao, F.-Q.; Zhang, Y.; Wan, Y.-G.; Jin, M. Slip model of the 2001 Kunlun mountain Ms 8.1 earthquake by SDM: Joint inversion from GPS and InSAR data. Chin. J. Geophys. 2016, 59, 2103-2112, (In Chinese with English abstract).

38. Wang, R. Computation of deformation induced by earthquakes in a multi-layered elastic crust-FORTRAN programs EDGRN/EDCMP. Comput. Geosci. 2003, 29, 195-207. [CrossRef]

39. Laske, G.; Masters, G.; Ma, Z.; Pasyanos, M. Update on CRUST 1.0-A1-degree global model of earth's crust. In Proceedings of the EGU General Assembly 2013, Vienna, Austria, 7-12 April 2013.

40. Yu, S.Y.; Luo, J.J.; Yang, Y.Y. Seismogenic structure of the Yangbi, Yunnan Ms6.4 earthquake on May 21, 2021 constraines by InSAR data. China Earthq. Eng. J. 2021, 43, 778-783, (In Chinese with English abstract).

41. Li, C.L.; Zhang, G.H.; Shan, X.J. Coseismic deformation and slip distribution of the Ms 6.4 Jiashi, Xinjiang earthquake revealed by Sentinel-1A SAR imagery. Prog. Geophys. 2020, 36, 481-488, (In Chinese with English abstract).

42. Xu, X.W.; Han, Z.J.; Yang, X.P. Seismotectionic Map of China and Its Adjacen Areas 2016; Seismological Press: Beijing, China, 2016; (In Chinese with English abstract).

43. King, G.C.P.; Stein, R.S.; Lin, J. Static stress changes and the triggering of earthquakes. Bull. Seismol. Soc. Am. 1994, 84, 935-953. [CrossRef]

44. Ji, L.Y.; Liu, C.J.; Xu, J.; Liu, L.; Long, F.; Zhang, Z.W. InSAR obervation and inversion of the seismogenic fault for the 2017 Jiuzhaigou MS7.0 earthquake in china. Chin. J. Geophys. 2017, 60, 4069-4082, (In Chinese with English abstract).

45. Stein, R.S.; King, G.C.P.; Lin, J. Change in Failure Stress on the Southern San Andreas Fault System Caused by the 1992 Magnitude = 7.4 Landers Earthquake. Science 1992, 258, 1328-1332. [CrossRef]

46. Wessel, P.; Smith, W. New, improved version of generic mapping tools released. EOS Trans. AGU 1998, 79, 579. [CrossRef] 